\title{
The Use of Markov Model in Continuous Time for Prediction of Rainfall for Crop Production
}

\author{
Abubakar U. Y., Lawal A., Muhammed A. \\ Department of Mathematics and Statistics, Federal University of Technology, Minna, Nigeria.
}

\begin{abstract}
In a first order Markov process, if the state is known for any specific values of the time parameter, that information is sufficient to predict the next behavior of the process beyond that point. This principle was used to formulate a four-state model in continuous time to study the annual rainfall data with respect to the annual rainfall distribution for crop production in minna. It was observed that if it is low rainfall in a given year, it would take at most $25 \%, 33 \%$ and $27 \%$ of the time to make a transition to moderate rainfall also well spread, high rainfall, and moderate rainfall but not well spread respectively in the far future. Thus given the rainfall in a year, it is possible to determine quantitatively the probability of finding rainfall in other states in the following year and in the long run. This is an important information that could assist the farmers to plan strategies for high crop production in the region.
\end{abstract}

Keywords: Markov Model, Transition probability, Annual rainfall, Crop production.

\section{Introduction}

Crop production is the major activity of people that live in Minna and the surrounding. Rainfall is the main source of water for growing crops in Nigeria because bump harvest and lean years depend on annual rainfall quantity and variability. Several attempts have been made to support the farmer with information services so that they could boost crop production in the face of variability and uncertainty of annual rainfall with mathematical models. In [1] was modified the Chapman-Kolmogorov Equation (CKE) and applied it to model the daily precipitation data of Abeokuta, Ogun State, Nigeria. Presented in [6] is the application of SemiMarkov model to study desert encroachment in Nigeria in view of the adverse effect of short rainfall on crop production in the region. Reported in [2] is a 7-State Markov Model to study the annual rainfall in Nadu, India . This paper considers the Markov chain model reported in [9] where the application was made in discrete state and time and then attempt to improve on it so as to provide some quantitative prediction in continuous time.

\section{The Model Equations}

As contained in [5], a continuous time stochastic process $\{X(t)\}$ is an infinite family of random variables indexed by the continuous real variable $t$, that is for any fixed $t, X(t)$ is a random variable and the collection of all these (for all $t$ ) is a stochastic process. We shall take $t$ as time, so we may expect $X\left(t_{1}\right)$, the random variable at time $t_{1}$ to be dependent on $X\left(t_{0}\right)$, where $t_{0}<t_{1}$ but not upon $X\left(t_{2}\right)$, where $t_{2}>t_{1}$. We refer to the value of $X\left(t_{1}\right)$ as the state of the process at the time t. we assume $X(t)$ are discrete state continuous time stochastic process.

We consider a finite (or countably infinite) set of point $\left(\mathrm{t}_{0} \mathrm{t}_{1 \ldots \ldots \ldots . . . . .} \mathrm{t}_{\mathrm{n}, \mathrm{t}} \mathrm{t}\right), \mathrm{t}_{\mathrm{o}}<\mathrm{t}_{1}<\mathrm{t}_{2}<\ldots<\mathrm{t}_{\mathrm{n}}<\mathrm{t}$ and $\mathrm{t}, \mathrm{t}_{\mathrm{r}}$ $\in \mathrm{T}(\mathrm{r}=1,2, . . \mathrm{n})$

where $\mathrm{T}$ is the parameter space of the process $\{\mathrm{X}(\mathrm{t})\}$. The dependence exhibited by the process $\mathrm{X}(\mathrm{t}), t \in T$ is called "Markov dependence" for given values of $\mathrm{X}\left(\mathrm{t}_{1}\right), \mathrm{X}\left(\mathrm{t}_{2}\right) \ldots \mathrm{X}\left(\mathrm{t}_{\mathrm{n}}\right)$ depends only on $\mathrm{X}\left(\mathrm{t}_{\mathrm{n}}\right)$ which is the most recent known value of the process.

That is, if $P\left[X(t) \leq X \mid X\left(t_{n}\right)=X_{n}, X\left(t_{n-1}\right)=X n-1, \ldots \ldots, X\left(t_{0}\right)=X_{0}\right]$

$$
\begin{array}{ll}
= & P\left[X(t) \leq X \mid X\left(t_{n}\right)=X_{n}\right] \\
= & F\left(X_{n}, X: t_{n}, t\right)
\end{array}
$$

The stochastic process exhibiting this property is called a Markov process. In a Markov process, therefore, if the state is known for any specific values of the time parameter $t$ that information is sufficient to predict the next behavior of the process beyond that point.

As a consequence of the property given by (1) we have the following relation

$F\left(x_{0}, x: t_{0}, t\right)=\int_{y \in s} F(y, x, \tau, t) d F\left(x_{0}, y, t_{0}, \tau\right)$

where $\mathrm{t}_{\mathrm{o}}<\tau<\mathrm{t}$ and $\mathrm{S}$ is the state space of the process $\mathrm{X}(\mathrm{t})$. 
Equation (2) is called the Chapman Kolmogorov equation for the process. These are basic equation in the study of Markov processes they enable us to build a convenient relationship for the transition probabilities between any points in $\mathrm{T}$ at which the process exhibits the property of Markov dependence.

Another statement of the Chapman Kolmogorov equation and the proof is given below, [7].

$P_{i}(t+s)=P(X(t+s)=j \mid X(0)=i)$ (definition)

$$
=\sum_{k} P(\mathrm{X}(\mathrm{t}+\mathrm{s})=\mathrm{j}, \mathrm{X}(\mathrm{t})=\mathrm{k} \mid \mathrm{X}(0)=\mathrm{i}) \text { (Marginal from joint) }
$$

$$
\begin{aligned}
& =\sum_{k} P(\mathrm{X}(\mathrm{t}+\mathrm{s})=\mathrm{j} \mid \mathrm{X}(\mathrm{t})=\mathrm{k}, \mathrm{X}(0)=\mathrm{i}) \mathrm{P}(\mathrm{X}(\mathrm{t})=\mathrm{k} \mid \mathrm{X}(0)=\mathrm{i}) \quad \text { (Joint from Conditional) } \\
& =\sum_{k} P(\mathrm{X}(\mathrm{t}+\mathrm{s})=\mathrm{j} \mid \mathrm{X}(\mathrm{t})=\mathrm{k}) \mathrm{P}(\mathrm{X}(\mathrm{t})=\mathrm{k} \mid \mathrm{X}(0)=\mathrm{i}) \text { (Markov assumption) } \\
= & \sum_{k} P(\mathrm{X}(\mathrm{s})=\mathrm{j} \mid \mathrm{X}(0)=\mathrm{k}) \mathrm{P}(\mathrm{X}(\mathrm{t})=\mathrm{k} \mid \mathrm{X}(0)=\mathrm{i})(\text { Stationary) } \\
= & \sum P_{i k}(s) P_{k j}(t) \text { (definition) }
\end{aligned}
$$

Thus $P_{i j}(t+s)=\sum P_{i k}(t) P_{k j}(s)$

This is the Chapman Kolmogorov equation in general form. We shall use it in the special form of

$$
P_{i j}(t+\delta t)=\sum P_{i k}(t) P_{k j}(\delta t)
$$

This equation requires the Markov assumption to permit a multiplication of the probabilities referring to events during $\mathrm{t}$ and to event during $\delta t$, it also requires stationary to permit use of the same probability functions for this interval $t$ and for the later interval $\delta t$.

A Markov process is said to be time homogeneous or stationary if

$$
\left.P\left(X\left(t_{2}\right)=j \mid X\left(t_{2}\right)=i\right)=P X\left(t_{2}-t_{1}\right)=j \mid X(0)=i\right)
$$

For all $i, j, t_{1}$, and $t_{2}$ such that $t_{1}<t_{2}$

In words the process is Stationary if these conditional probabilities depend on the interval between the events rather than an absolute time.

A Stationary Markov Process is completely described by its transition probability functions, denoted $P_{i}(t)$ where

$$
P_{i j}(t)=P(X(t)=j \mid X(0)=i)
$$

We observe that $P_{i j}(t)$ function is probabilities, for all $t$, they are non negative bounded function because they must lie between 0 and 1

$\mathrm{P}_{\mathrm{ij}}(0)=\mathrm{P}(\mathrm{X}(0)=\mathrm{j} \mid \mathrm{X}(0)=\mathrm{i})$ clearly, for $\mathrm{i}$ different from $\mathrm{j}$

$\mathrm{P}_{\mathrm{ij}}(0) \quad=0$ and for $\mathrm{i}$ equal to $\mathrm{j}, \mathrm{Pjj}(0)=1$, if we fix $\mathrm{i}$ and vary $\mathrm{j}$ over all states, the sum of the $\operatorname{Pi}(\mathrm{t})$ must equals 1 (for all t)

$$
\begin{aligned}
& \sum_{j} P_{i j}(t)=\sum_{j} P(X(t)=j / X(0)=i) \\
& =\mathrm{P}(\mathrm{X}(\mathrm{t})=\text { any of its possible states } \mid \mathrm{X}(0)=\mathrm{i} \\
& =1
\end{aligned}
$$

Under the assumption that the $\mathrm{P}_{\mathrm{ij}}(\mathrm{t})$ are continuous functions of time we can express $\mathrm{P}_{\mathrm{ij}}$ for small $\delta t$ by the use of Maclaurin's series.

$$
p_{i j}(\delta t)=p_{i j}(0)+p_{i j}^{\prime}(0) \delta t+o\left(\delta t^{2}\right)
$$

where $o\left(\delta t^{2}\right)$ represents all terms of the order of $(\delta t)^{2}$ or higher. If we consider this expression for $\mathrm{i} \neq \mathrm{j}$, and Let $q_{i j}=p_{i j}^{\prime}(0)$ we obtain

$$
p_{i j}(\delta t)=q_{i j} \delta t+o\left(\delta t^{2}\right)
$$


We may think of this as a linear approximation to $\mathrm{P}_{\mathrm{ij}}(\mathrm{t})$ which is a good approximation as long as $\delta t$ is small. The $\mathrm{q}_{\mathrm{ij}}$ is called the transition rate from $\mathrm{i}$ to $\mathrm{j}$ since $\mathrm{P}_{\mathrm{ij}}(0)=0$ and this is the minimum value. We should be certain that $\mathrm{q}_{\mathrm{ij}}$ non-negative.

For $\mathrm{i}=\mathrm{j}$ the Maclaurin's series expansion yields

$p_{j j}(\delta t)=1+p_{j j}^{\prime}(0) \delta t+o\left(\delta t^{2}\right)$

let $q_{j j}=p_{j j}^{\prime}(0)$

we get the linear approximation

$p_{j j}(\delta t)=1+q_{j j} \delta t+o\left(\delta t^{2}\right)$

Since we know that $\mathrm{p}_{\mathrm{ij}}(0)=1$ and that is the maximum value we may be certain that $\mathrm{q}_{\mathrm{ij}}$ is non-positive.

If we now consider the Chapman-Kolmogorov equation

$$
p_{i j}(t+\delta t)=\sum_{k} p_{i k}(t) p_{k j}(\delta t)
$$

for small $\delta t$, and substitute our linear approximation, we get

$$
\begin{aligned}
& p_{i j}(t+\delta t)=p_{i j}(t)\left[1+q_{j j} \delta t+o\left(\delta t^{2}\right)\right]+\sum_{k \neq j} p_{i k}(t)\left[q_{k j} \delta t+o\left(\delta t^{2}\right)\right] \\
& \frac{p_{i j}(t+\delta t)-p_{i j}(t)}{\delta t}=p_{i j}(t) q_{j j}+\frac{p_{i j}(t) o\left(\delta t^{2}\right)}{\delta t}+\sum_{k \neq j}\left[p_{i k}(t) q_{k j}+\frac{p_{i k}(t) o\left(\delta t^{2}\right)}{\delta t}\right]
\end{aligned}
$$$$
=\sum_{k} p_{i k}(t) q_{k j}+\sum_{k} \frac{p_{i k}(t) o\left(\delta t^{2}\right)}{\delta t}
$$

Taking limit as $\delta t \rightarrow 0$

$$
\frac{d p_{i j}(t)}{d t}=\sum_{k} p_{i k}(t) q_{k j}
$$

In matrix form we have $\frac{d p(t)}{d t}=p(t) Q$

where $\frac{d p(t)}{d t}$ is the matrix whose $(i, j)^{t h}$ element is $\frac{d p_{i j}(t)}{d t}$,

$p(t)$ is the matrix whose $(i, j)^{t h}$ element is $p_{i j}(t)$, and $\mathrm{Q}$ is the matrix whose $(i, j)^{t h}$ element is $q_{i j}$

The elements of $\mathrm{Q}$ may be further related by extending the properties of $\mathrm{P}(\mathrm{t})$

In particular, since for each $\mathrm{i}$ 


$$
\begin{aligned}
& \sum_{j} p_{i j}(t)=1 \\
& \frac{d}{d t}\left[\sum_{j} p_{i j}(t)\right]_{t=0}=\left[\frac{d}{d t}(1)\right]_{t=0} \\
& \left.\sum_{j} \frac{d}{d t} p_{i j}(t)\right|_{t=0}=0 \\
& \sum_{j} q_{i j}=0
\end{aligned}
$$

In words, each row of Q must sum to zero. Since off-diagonal element in non negative, the diagonal element $q_{i i}$, must be equal in magnitude and opposite in sign to the sum of others in the same rows. That is

$$
q_{i i}=-\sum_{i \neq j} q_{i j}
$$

To obtain the solution to (3) the initial condition $P_{i}(0), i=1,2,3,4 \ldots$ must be specified

Taking the Laplace transform of (3) we obtained

$$
P(s)=p(0)(S I-Q)^{-1}
$$

Thus $\mathrm{p}(\mathrm{t})$ is obtained as the inverse transform of $\mathrm{P}(\mathrm{s})$, [4].

\section{APPLICATION}

Suppose that the amount of annual rainfall in Minna in a year is considered as a random variable $X$, the collection of this random variable over the years $n$ constitutes a stochastic process $X_{n}, \quad n=0,1,2,3 \ldots \ldots \ldots \ldots \ldots$ It is assumed that this stochastic process satisfies first order Markov property, [9].

It has been observed over the past ten years that the annual rainfall in Minna varied from $698 \mathrm{~mm}$ to $1423.4 \mathrm{~mm}$. It is known that the rainfall requirement for the major crops grown in the environment is within the range of $1000 \mathrm{~mm}-1200 \mathrm{~mm}$ and should spread fairly across from May to October in the year. The annual rainfall below or above this range and not spread well may lead to poor harvest, contained in [8].

Let the annual rainfall be modeled by four state Markov model.

State1: Low rainfall (Annual rainfall below $1000 \mathrm{~mm}$ )

State2: Moderate rainfall (Annual rainfall within the range $1000 \mathrm{~mm}-1201 \mathrm{~mm}$ also well spread)

State3: High rainfall (Annual rainfall above $1201 \mathrm{~mm}$ )

State4: Moderate rainfall (Annual rainfall within the range $1000 \mathrm{~mm}-1201 \mathrm{~mm}$ but not well spread)

On the basis of the observed data, the transition between the states is described by the transition diagram shown in figure1. 


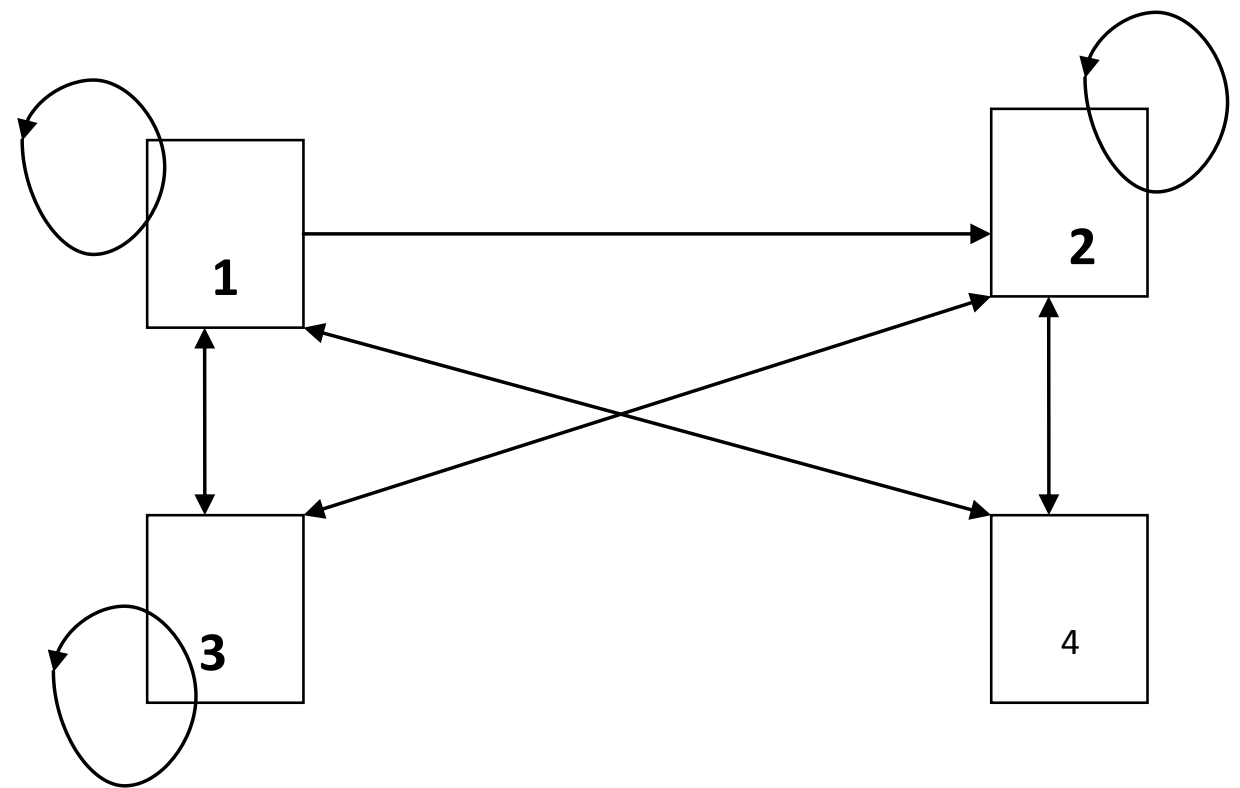

Fig 1 Transition diagram for the annual rainfall.

Consequently, we have the following transition matrix p.

$$
p=\left[\begin{array}{cccc}
P_{11} & P_{12} & P_{13} & P_{14} \\
0 & P_{22} & P_{23} & P_{24} \\
P_{31} & P_{32} & P_{33} & 0 \\
P_{41} & P_{42} & 0 & 0
\end{array}\right]
$$

The matrix $\mathrm{P}$ is homogeneous transition stochastic matrix and the transition probabilities $\mathrm{p}_{\mathrm{ij}}$ are fixed and independent of time. The transition probabilities must satisfy

$$
P_{i j} \geq 0, i, j=1,2,3,4 \text {. and } \sum_{j=1}^{4} P_{i j}=1, \quad i=1,2,3,4 \text {. }
$$

The summary statistics of the annual rainfall in Minna for a period of fourty one years is presented in tablel.

Table1:A summary statistics of annual rainfall in Minna between 1970-2010 and states distribution (Source; from [8] and [9]).

\begin{tabular}{|l|l|l|}
\hline Annual rainfall in $\mathrm{mm}$ & Frequency & State \\
\hline Above 1201 & 18 & 3 \\
\hline $1000-1201(\mathrm{WS})$ & 14 & 2 \\
\hline $1000-1201(\mathrm{NS})$ & 3 & 4 \\
\hline Below 1000 & 6 & 1 \\
\hline
\end{tabular}

WS: mean the annual rainfall that spread fairly across the rainy season

NS: mean annual rainfall that does not spread evenly across the rainy season

The transition between the states is recorded in the transition count matrix M shown below.

$$
M=\left[\begin{array}{cccc}
2 & 2 & 1 & 1 \\
0 & 6 & 6 & 1 \\
3 & 4 & 11 & 0 \\
1 & 2 & 0 & 0
\end{array}\right]
$$

Normalizing this matrix using equation (4) we obtain a Matrix A 


$$
A=\left[\begin{array}{cccc}
-4 & 2 & 1 & 1 \\
0 & -7 & 6 & 1 \\
3 & 4 & -7 & 0 \\
1 & 2 & 0 & -3
\end{array}\right]
$$

The Matrix A can be expressed as the expected value of the exponential distribution to get a Matrix Q.

$$
Q=\left[\begin{array}{cccc}
-2.50 & 0.5 & 1 & 1 \\
0 & -1.17 & 0.17 & 1 \\
0.33 & 0.25 & -0.58 & 0 \\
1 & 0.5 & 0 & -1.5
\end{array}\right]
$$

Solving equation (5) with the Matrix Q using maple software, we have the following set of equations.

$$
\begin{aligned}
& P_{12}(t)=0.2495604333-0.0090440077760 \ell^{-0.7708862413 t}-0.196577499 \ell^{-1.796647256 t}-0.04394867763 \ell^{-3.182466503 t} \\
& P_{13}(t)=0.3329363054+0.03252636670 \ell^{-0.7708862413 t}-0.2658836081 e^{-3.182466503 t}-0.099579064 e^{-1.76647256 t} \\
& P_{14}(t)=0.2668254778-0.3895921738 e^{-3.182466503 t}-0.01881100472 \ell^{-0.7708862413 t}+0.1415777007 \ell^{-1.796647256 t} \\
& P_{23}(t)=0.332936054-0.5476416039 \ell^{-0.7708862413 t}-0.09639085915 \ell^{-3.182466503 t}+0.311096156 \ell^{-1.796647256 t} \\
& P_{24}(t)=0.2668254778+0.3167180879 \ell^{-0.7708862413 t}-0.1412389612 \ell^{-3.182466503 t}-0.4423046045 \ell^{-1.796647256 t} \\
& P_{42}(t)=0.259560433+0.09201897185 \ell^{-0.770886241256 t}+0.0308565067 \ell^{-3.182466503 t}-0.3724359119 \ell^{-1.796647256 t} \\
& P_{43}(t)=0.3329363054-0.3309420955 \ell^{-0.7708862413 t}-0.1886719456 \ell^{-1.79664256 t}+0.1866777357 \ell^{-3.182466503 t} \\
& P_{41}(t)=0.1506777838+0.04752906760 \ell^{-0.7708862413 t}-0.4910681609 \ell^{-3.182466503 t}+0.2928613099 \ell^{-1.796647256 t}
\end{aligned}
$$


The Use Of Markov Model In Continuous Time For Prediction Of Rainfall For Crop Production

These equations are computed to have the transition probabilities contained in table 2 .

Table 2: The Transition Probabilities

\begin{tabular}{|l|l|l|l|l|l|l|l|l|}
\hline $\mathrm{t}$ & $\mathrm{p}_{12}(\mathrm{t})$ & $\mathrm{p}_{13}(\mathrm{t})$ & $\mathrm{p}_{14}(\mathrm{t})$ & $\mathrm{p}_{23}(\mathrm{t})$ & $\mathrm{p}_{24}(\mathrm{t})$ & $\mathrm{P}_{42}(\mathrm{t})$ & $\mathrm{p}_{43}(\mathrm{t})$ & $\mathrm{p}_{41}(\mathrm{t})$ \\
\hline 0 & 0.000000 & 0.000000 & 0.000000 & 0.000000 & 0.000000 & 0.000000 & 0.000000 & 0.000000 \\
\hline 1 & 0.210952 & 0.320438 & 0.265443 & 0.127194 & 0.334123 & 0.231639 & 0.156294 & 0.200866 \\
\hline 2 & 0.242142 & 0.33670 & 0.266024 & 0.224132 & 0.322194 & 0.259061 & 0.257246 & 0.168060 \\
\hline 3 & 0.247762 & 0.335683 & 0.265581 & 0.280133 & 0.296152 & 0.256972 & 0.299326 & 0.156684 \\
\hline 4 & 0.248997 & 0.33435 & 0.26607 & 0.308091 & 0.280995 & 0.253493 & 0.317638 & 0.153075 \\
\hline 5 & 0.249344 & 0.333613 & 0.266445 & 0.321373 & 0.27348 & 0.251462 & 0.325901 & 0.151721 \\
\hline 6 & 0.249468 & 0.333253 & 0.266644 & 0.327576 & 0.26992 & 0.250455 & 0.329689 & 0.151150 \\
\hline \hline 7 & 0.249519 & 0.330834 & 0.266741 & 0.330455 & 0.26826 & 0.249976 & 0.331435 & 0.150894 \\
\hline 8 & 0.249541 & 0.333004 & 0.266786 & 0.331789 & 0.267489 & 0.249753 & 0.332242 & 0.150778 \\
\hline 9 & 0.249552 & 0.332968 & 0.266807 & 0.332405 & 0.267133 & 0.249650 & 0.332615 & 0.150724 \\
\hline 10 & 0.249556 & 0.332951 & 0.266682 & 0.33269 & 0.266968 & 0.249602 & 0.332788 & 0.150699 \\
\hline 11 & 0.249559 & 0.332943 & 0.266822 & 0.332823 & 0.266891 & 0.24958 & 0.332868 & 0.150688 \\
\hline 12 & 0.249560 & 0.332939 & 0.266824 & 0.332884 & 0.266856 & 0.249569 & 0.332905 & 0.150682 \\
\hline 13 & 0.24956 & 0.332938 & 0.266825 & 0.332912 & 0.26684 & 0.249565 & 0.332922 & 0.15068 \\
\hline
\end{tabular}

The transition probabilities are illustrated with graph shown in figure2.

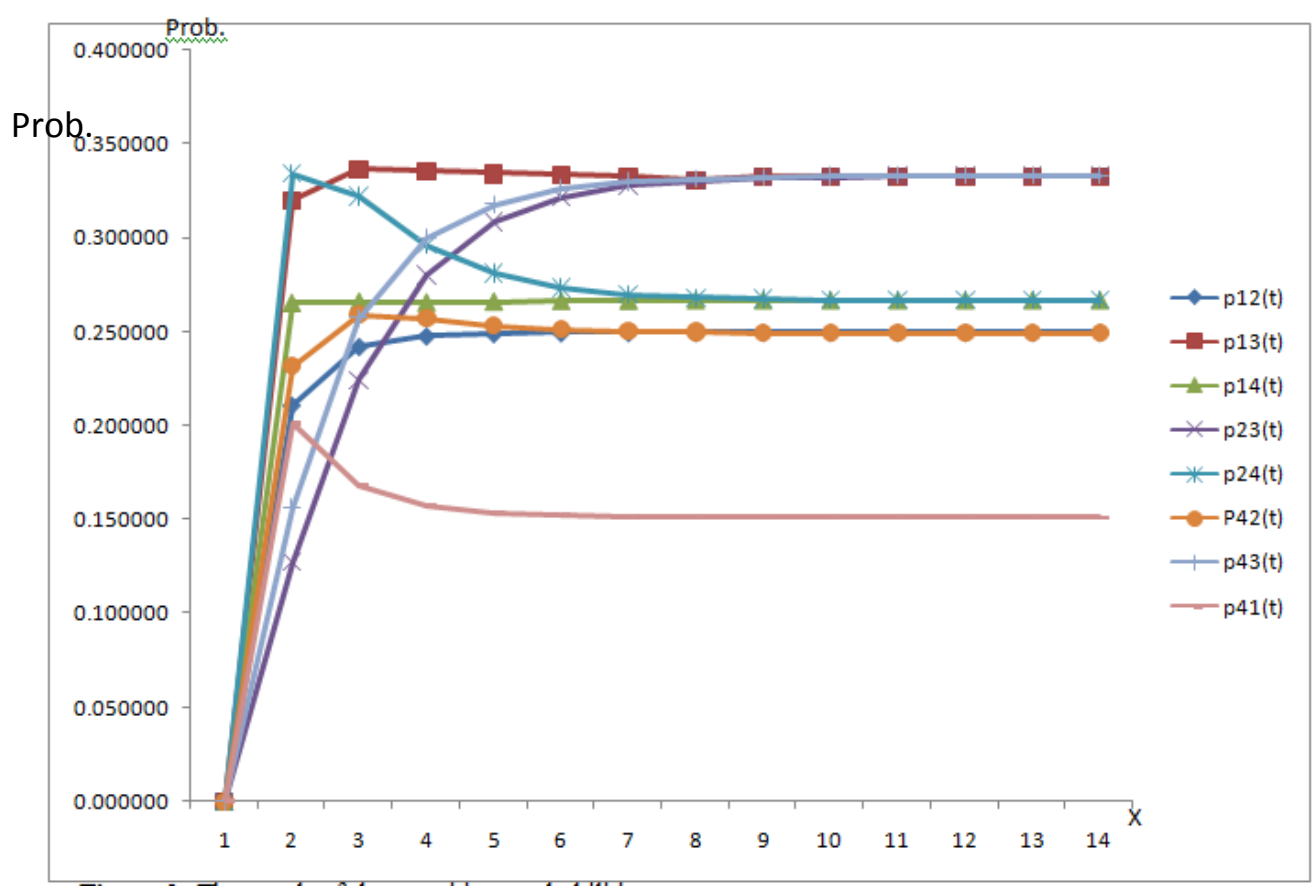

Figure 2: The graph of the transition probabilities. 


\section{Discussion of Results}

The result is presented in Table 2 and illustrated with graph in figure 1. The model enables us to determine the values of $P_{11}(t), P_{12}(t), P_{13}(t)$,

$\mathrm{P}_{44}(\mathrm{t})$ respectively at any time $\mathrm{t}$.

It is observed that $\mathrm{p}_{23}(\mathrm{t})$ and $\mathrm{p}_{43}(\mathrm{t})$ rose steadily and become stable at about $\mathrm{t}=7$, but $\mathrm{p}_{12}(\mathrm{t})$ become stable about $\mathrm{t}=4$. This is unlike others that rose and fall to become stable sharply for $\mathrm{t}<2$ respectively. It can be seen from the table that it takes at most $0.25,0.33$ and 0.27 of the time to make transition from state 1 to states 2,3 and 4 respectively. It takes also at most about 0.33 and 0.27 of the time to make a transition from state 2 to state 3 and state 4 respectively. Similarly it takes at most 0.25 and 0.33 of the time to make a transition from state 4 to state 2 and state 3 respectively. Finally, it takes at most 0.20 of the time to make a transition from state 4 to state 1 These are the equilibrium transition probabilities. For instance, if it low rainfall in a given year, it would take at most $25 \%, 33 \%$ and $27 \%$ to have moderate rainfall also well spread, high rainfall, and moderate rainfall but not well spread in the respectively in the long run. Thus given the rainfall in a year it is possible to determine quantitatively the probability of finding rainfall in other states in the following year(s) and in the long run. This is important information that could be useful to the farmers in planning strategy for high crop production in minna and the environment.

\section{References}

[1] Akintunde A.A, Asiribo O.E. Adebanji A.O. Adelakun A.A Agwuegbo S.O.N. (2008) Stochastic modelling of daily precipitation in Abeokuta, proceedings of the third Confersence on science and National Development pp108-118 www.unaab.edu.ng/journal/index.php/COLNAS/article/.../150/153. Accessed 15/10/2012.

[2] Tamil S. and Samuel S.(2011).Universal Journal of Environmental Research and Technology vol.1 Issue4 pp566-570.

[3] Howard R.A.(1960) Dynamic programming and Markov processes. The M.I.T.PRESS, Massachusetts.

[4] Korve K.N.(2000). A Three-State Continuous Time Markov Model for asthma process. ABACUS, The journal of Mathematical Association of Nigeria. Volume27, Number2, pp 33-46.

[5] Bhat,U.N. (1984) 'Element of Applied Stochastic processes', John Wiley, New York.

[6] Okorie C. (2012). Semi-Markov Model in Discrete time and States and the Application to Desertification Study in Nigeria. Unpublished MSc. Thesis. Department of Mathematics and Statistics, Federal University of Technology, Minna, Nigeria.

[7] Korve K N(1994). Operations Research MAT537, Unpublished lecture notes. Department of Mathematics, University of Jos Nigeria.

[8] Lawal Adamu(2012), The Use of Markov Model in Predicting the Rainfall Pattern forCropProduction. Unpublished MTech Thesis, Department of Mathematics and Statistics, Federal University of Technology,Minna. Nigeria

[9] Abubakar U.Y. and Lawal A. Muhammed A., (2013), Markov Chain Model and Its Application to annual Rainfall Distribution for Crop Production. Submitted. 